\title{
Some aspects of the pharmacology of oral anticoagulants
}

\author{
The pharmacology of oral anticoagulants is discussed with particular reference to data \\ of value in the management of therapy. The importance of individual variability in \\ response and drug interaction is stressed. Other effects of these agents which may \\ have clinical utility are noted.
}

William W. Coon, M.D., and Park W. Willis III, M.D., Ann Arbor, Mich. The Departments of Surgery (Section of General Surgery) and Medicine, University of Michigan Medical School

In the twenty-five years since the isolation of the hemorrhagic factor in spoiled sweet clover, ${ }^{25}$ the gradually increasing utilization of oral anticoagulants for the prevention and therapy of thromboembolic disease has made them one of the most widely used groups of pharmacologic agents. This review is restricted to aspects of the pharmacology of these agents which may be important to their proper clinical utilization.

\section{Relation of structure to function}

The oral anticoagulants have been divided into four main groups on the basis of chemical structure (Fig. 1).

Although a number of investigators have attempted to define the structural characteristics necessary for the production of an anticoagulant effect, each theory has been partially invalidated by the discovery of exceptions. Arora and Mathur ${ }^{6}$ have recently proposed that anticoagulant activity of coumarins is governed not by in-

Supported by grants from the Michigan Heart Association and Grant FR-05383 from the National Institutes of Health. dividual structural features but by a combination of several: molecular shape, increased activity with 6 membered heterocyclic rings with a substituent in position 8 and with a methoxyl rather than a free hydroxl group. Also important is the demonstration that levorotatory warfarin is seven times more active than its enantiomer. ${ }^{179}$ As Hunter and Shepherd ${ }^{72}$ have pointed out, the failure to obtain a precise correlation between structure and anticoagulant activity is "not surprising in view of the influence of small structural changes on such variables as solubility, rate of absorption, ease of distribution, degree of binding by tissues or plasma protein and rate of detoxication and excretion."

All coumarin-type anticoagulants are 4hydroxycoumarins. Mead and associates have shown that 3-, 5-, 6-, 7-, and 8-hydroxycoumarins are phenolic in nature and are metabolized in rabbits principally by direct conjugation with glucuronic and sulfuric acids. However, 4-hydroxycoumarin differs from its isomers in conjugating only with glucuronic acid. It forms no ethereal sulfates since it is a relatively 
1. Compounds with two coumarin rings: "Dicoumarols"<smiles>[R]C(c1c(O)c2ccccc2oc1=O)c1c(O)c2ccccc2oc1=O</smiles>

Bishydroxycoumarin $\quad \mathrm{R}=\mathrm{H}$

Ethylbiscoumacetate $\mathrm{R}=\mathrm{COOC}_{2} \mathrm{H}_{5}$

2. 3-substituted 4-hydroxycoumarins: "Mono-coumaro1s"<smiles>[R]c1c(O)c2ccccc2oc1=O</smiles>

Phenprocoumon<smiles>[R]C([R])c1ccccc1</smiles>

Acenocoumarin

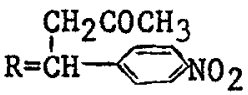

Warfarin

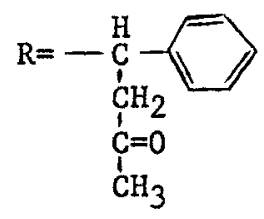

3. Cyclic acetals: "Cyclocoumarols"

Cyclocumarol<smiles>[R]CC([R2])([R])Oc1c(CC([R11])[R16])c(=O)oc2ccccc12</smiles><smiles>[R17]c1ccccc1</smiles>

$\mathrm{R}_{2} \mathrm{CH}_{3}$

$\mathrm{R}_{3} \mathrm{CH}_{3}$

4. Indandiones<smiles>[R]C1=C(O)c2ccccc2C1=O</smiles>

\section{Phenindione}

Diphenadione

Anisindione<smiles>[R]C(=O)OC(c1ccccc1)c1ccccc1-c1ccc(C)cc1</smiles>

Chlorphenylind andione

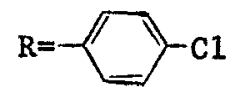

Fig. 1. Four main groups of oral anticogulants on the basis of chemical structure.

strong acid with a pK of 5.8.98 This difference may have pharmacologic implications since almost all other naturally occurring derivatives of coumarin are either 7-hydroxy derivatives or 7-O-ethers, and the 7-position may be more susceptible to biologic attack. ${ }^{99}$

\section{Newer agents}

A number of reports concerning new oral anticoagulants have appeared in the past several years. Most have been newly synthesized derivatives of 4-hydroxycou-

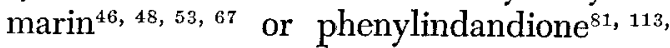
162 without unique properties or clinical 
utility. The isolation of a complex 4phenylcoumarin with anticoagulant and quinidine-like activity from an Indian medicinal plant ${ }^{7}$ is of interest chiefly because of the rarity of naturally occurring 4-substituted coumarins.

New compounds of potential interest have recently been prepared by esterification of polyvinyl alcohol with the lactone of bis 4-hydroxy-3-coumaryl acetic acid; the product is a copolymer of vinyl alcohol and the vinyl ester of pelentanic acid. Fractions of varying molecular weight and degree of esterification have been obtained. Anticoagulant activity has been observed in rabbits after oral or intravenous administration of a fraction of 30,000 molecular weight; fractions of higher molecular weight were very toxic. After a single dose, an anticoagulant effect was observed for as long as 15 days; as with other coumarin derivatives, onset of a measurable anticoagulant effect took place after a lag period of 20 to 24 hours. An unexpected aspect of these studies was the discovery that this agent produced a pronounced increase in coagulation time of whole blood as well as prothrombin time. ${ }^{128}$

\section{Mechanism of action}

The keto isomer of 4-hydroxycoumarin has a close structural relationship to menadione (vitamin $K_{3}$ ). Substitution of a methoxy group for the methyl in menadione (2-methyl-1,4 naphthoquinone) converts this synthetic vitamin $\mathrm{K}$ into a compound with anticoagulant activity. ${ }^{102} \mathrm{Cou}-$ marin and related anticoagulants are thought to act by means of some antagonistic effect upon the action of vitamin $\mathrm{K}$. Although originally postulated to be competitive inhibitors of vitamin $\mathrm{K}$, Lowenthal and MacFarlane ${ }^{90}$ have presented data derived from experiments with the simultaneous administration of warfarin and moderate doses of vitamin $K_{1}$ to rats which they have interpreted as indicating that the antagonism between these two agents is neither of the classical competi- tive or noncompetitive type. They propose that the action of an oral anticoagulant depends upon the irreversible inhibition of transport of vitamin $\mathrm{K}_{1}$ to its intracellular site of action in the liver. ${ }^{89}$ With a much larger dose of vitamin $\mathbf{K}_{\mathbf{1}}$, however, this inhibition can be surmounted, possibly because vitamin $K$ can enter the cell by an alternate mechanism which cannot be inhibited by oral anticoagulants. ${ }^{90}$ As to its intracellular site of action, Olson ${ }^{117}$ postulates that vitamin $\mathrm{K}$ may be necessary for the derepression of a regulator gene which controls the synthesis of clotting factors and that an anticoagulant may interfere with the action of vitamin $\mathrm{K}$ on the repressor substance. There is no evidence in support of any chemical alteration of prothrombin (or other clotting factors) or inhibition of its release or any increased rate of utilization or degradation. ${ }^{65}$

None of the oral anticoagulants has a significant anticoagulant effect when added to blood in vitro. When these agents are administered to animals or man, the functional activities of several clotting factors decrease. A decrease in activity of factor VII is followed sequentially by decreases in factors IX, $\mathrm{X}$, and II (true prothrombin). The rate of decrease in functional activity of these coagulation factors appears to be related to the half-lives of the individual proteins. After termination of therapy, these clotting factors return to normal levels in the same order. ${ }^{79}$ All anticoagulants produce the same effect. Johnson, ${ }^{78}$ who proposes that purified prothrombin can be converted to factor VII or factor IX by varying the activators, has suggested that the actions of oral anticoagulants on these multiple clotting factors may be interrelated, possibly representing minor structural alterations of a single protein.

\section{Inhibition of thrombosis}

The therapeutic value of oral anticoagulants in the prevention of thrombus formation or inhibition of propagation of pre- 
existing thrombi has been attributed to their effects in reducing activities of the above-mentioned clotting factors. In recent years contradictory data have appeared concerning a possible additional effect upon platelet function. Platelets play an important role in the initiation of thrombus formation, particularly in arteries. The true effect of oral anticoagulant therapy upon platelets is difficult to assess because of differences in experimental methods (some in vitro, others in vivo), different animal species, and measurement of differing effects (adhesiveness, aggregation, thrombus weight, etc.). In man, adequate doses of bishydroxycoumarin have been reported to bring about a prolongation of platelet survival and a decrease in platelet turnover and platelet adhesiveness. ${ }^{108,109,}$ 161,186 Inadequate dosage may have the opposite effect. ${ }^{70}$ Platelet-rich plasma from anticoagulant-treated patients tested in vitro in the Chandler apparatus shows a significant increase in time required for platelet aggregation. ${ }^{44}$ However, when electrically induced thrombi are produced in hamster cheek pouches, oral anticoagulants suppress formation of a fibrin thrombus but have no significant effect upon the development of a platelet thrombus. ${ }^{14}$

The data of greatest value to clinicians in the assessment of the therapeutic utility of oral anticoagulants are those derived from well-designed clinical trials. However, the effects of these agents on both initiation and resolution of thrombi are difficult to study in man. Numerous investigations of the antithrombogenic effect of anticoagulants have been conducted in experimental animals, but, since our knowledge of the pathogenesis of thrombosis is limited, results obtained in animals may not be directly applicable to the management of human disease. In general, heparin is more effective than oral anticoagulants in prevention of the formation of experimental thrombi. Administration of an adequate dose of oral anticoagulant is critical for the demonstration of an antithrombotic effect; the greater the prolongation of one- stage prothrombin time, the less the incidence of thrombosis. Thrombus formation in rats is not reduced by bishydroxycoumarin unless prothrombin time is twice normal or greater; in fact, the incidence of thrombosis in animals receiving a small dose of drug is higher than that in controls. ${ }^{18}$ In experiments with "serum thrombosis," the antithrombotic effect of bishydroxycoumarin is demonstrable only if the drug has been administered for one week or more before thrombosis is produced (unless very massive doses of drug are administered ). ${ }^{178}$ This delay in demonstration of antithrombotic effect is not present if thrombosis is produced by vascular injury. ${ }^{77}$

If a comparable delay in appearance of antithrombotic effect is present in human beings with thrombotic disease, these findings may have implications for clinical therapy. The thrombus produced by injection of serum into an occluded venous segment is similar histologically, and probably in pathogenesis, to the "stasis" thrombus seen so frequently in the deep veins of the leg. Optimal therapy of patients with deep venous thrombosis may require simultaneous administration of heparin and an oral anticoagulant until the maximum therapeutic effectiveness of the oral anticoagulant has been achieved.

In animals the administration of oral anticoagulants has produced an increase in the rate of recanalization of arterial ${ }^{187}$ and venous thrombi ${ }^{188}$; this was not due to any demonstrable systemic fibrinolytic activity.

\section{Absorption}

Probably only a small fraction of orally administered drug is absorbed in the stomach, ${ }^{1}$ since, as organic acids, oral anticoagulants are considerably more soluble in alkaline solutions. The gastric content of free hydrochloric acid, however, does not have a detectable influence upon rate of onset of anticoagulant effect in man. ${ }^{84}$ In general, rate and completeness of gastrointestinal absorption are not important 
determinants of rapidity of "prothrombin" response, since differences in time of onset of effect vary little when oral and intravenous administration are compared. Drug can usually be detected in plasma within one to two hours after ingestion. Although individual drugs are detectable in plasma at essentially the same time, the peak concentration of some agents (e.g., bishydroxycoumarin, warfarin) is reached after a considerably longer interval than with other agents (ethylbiscoumacetate, phenindione). ${ }^{176}$

On the basis of stool content, absorption is usually complete. An exception is an occasional report of poor absorption of both coumarins and indandiones which appears to be related chiefly to errors in compounding or cơmpression of tablets, ${ }^{123,}{ }^{176}$ although other factors may also be involved. ${ }^{1}$ Response to two preparations of the same anticoagulant may differ by as much as 50 per cent. ${ }^{172}$ Bishydroxycoumarin is more slowly and less completely absorbed when given as a tablet rather than as a solution or powder. In vitro tests of the rate of disintegration of tablets are not good predictors of response in vivo. ${ }^{145}$

Pretreatment of human subjects with heptabarbital appears to influence absorption of bishydroxycoumarin. Increased excretion of bishydroxycoumarin in the stool persists for several weeks after withdrawal of the barbiturate. ${ }^{1}$

The solubility in water of a drug may also influence its absorption. Warfarin sodium is 75,000 times more soluble than bishydroxycoumarin in aqueous solutions; in contrast to bishydroxycoumarin, unchanged warfarin has not been recovered from the stool. ${ }^{1}$ Warfarin is the only "oral" anticoagulant supplied in a form for intravenous or intramuscular administration.

\section{Distribution and metabolism}

Satisfactory and relatively simple methods are available for the determination of the majority of these drugs; most techniques are based on the original method for determination of bishydroxycoumarin devised by Axelrod and associates. ${ }^{8}$ These have been used, along with isotopically labeled compounds, to study relations between plasma levels, tissue distribution, and duration of anticoagulant effect.

The duration of anticoagulant effect correlates reasonably well with the interval in which the drug is retained in plasma ${ }^{174}$ and in liver. ${ }^{75}$ On the basis of serial determinations of plasma levels of individual drugs, Weiner ${ }^{174}$ has classified oral anticoagulants by rate of fall from the peak plasma level as rapid (ethylbiscoumacetate: 15 to 45 per cent per hour); intermediate (acenocoumarin, phenindione: 4 to 15 per cent per hour); slow (bishydroxycoumarin, cyclocumarol, warfarin, phenprocoumon, anisindione, chlorphenindione: 15 to 20 per cent per day); and ultraslow (diphenadione: less than 15 per cent per day). Within moderate dosage limits, the higher the initial dose the more rapid the fall in "prothrombin" activity. In general, the more rapid the fall in blood level the more frequently a dose must be administered in order to maintain a stable therapeutic effect.

However, the peak in blood level of a given drug is not directly associated with the maximum depression of "prothrombin" activity $^{24}$ which may occur 12 hours to three or more days later. In addition, because of extensive individual variability, Weiner ${ }^{174}$ has not been able to correlate depression of prothrombin activity with the concentration of drug in plasma. Recently, however, Nagashima and colleagues $^{110}$ have reported an essentially linear relationship between intensity of "prothrombinopenic" response and the logarithm of the dose of warfarin or its concentration in human plasma. This experiment should be repeated with another oral anticoagulant, since warfarin may be the only oral anticoagulant in which plasma half-life is independent of dose. ${ }^{124}$ The rates of disappearance of bishydroxycoumarin and ethylbiscoumacetate from plasma decrease as the doses of drug increase. ${ }^{174}$ 
Protein binding may also influence rapidity of onset and duration of effect. The extent of protein binding (99 per cent for bishydroxycoumarin, 97 per cent for warfarin, 90 per cent for ethylbiscoumacetate) roughly parallels the biologic half-life and duration of prothrombinopenic effect. ${ }^{123}$ Since at any given time less of the latter drug is bound, the considerably higher concentration of free drug may play a role in its comparatively rapid onset of effect. As will be discussed later, other agents which alter protein binding have a significant influence upon anticoagulant effect. The strongest and greatest percentage of binding is to albumin. ${ }^{177}$ O'Reilly and associates $^{120,123}$ have proposed that the high degree of nonelectrostatic binding of warfarin to albumin and its nonpolar character account for the sustained levels of this drug in plasma, the absence of urinary loss, and its small volume of distribution.

Uptake of drug by erythrocytes is variable, being about 20 per cent for bishydroxycoumarin and phenindione (rabbit), ${ }^{73}$ 9 to 18 per cent for ethylbiscoumacetate (rat), ${ }^{69}$ and less than 1 per cent for warfarin (man). ${ }^{123}$ Warfarin is not detectable in the cerebrospinal fluid (rabbit) ${ }^{73}$ Bishydroxycoumarin and other oral anticoagulants cross the placenta, reaching concentrations in the plasma of the fetus almost comparable to those of the mother. ${ }^{140}$ These agents appear in breast milk in sufficient concentration to induce significant depression of prothrombin activity. ${ }^{101}$

The majority of drug is distributed between plasma and liver ${ }^{29,30}$ with lesser amounts in kidney and intestinal tract. The rate of elimination follows the kinetics of a first-order reaction, probably reflecting the rate of metabolic transformation. When $\mathrm{C}^{14}$-labeled bishydroxycoumarin is administered to rats, ${ }^{30}$ most of the radioactivity is detectable in the feces within five days. Only a small amount appears in the urine. However, if the bile duct is occluded, the major portion of radioactivity appears in the urine. In other species ${ }^{73}, 85$, ${ }^{106}$ greater amounts of radioactivity normal- ly appear in the urine, presumably through reabsorption from the intestinal tract after biliary excretion. The metabolic products of oral anticoagulants excreted in urine have not been fully identified. The only anticoagulant excreted unaltered in the urine in significant amounts is acenocoumarin. ${ }^{130}$ Metabolites of several coumarin derivatives with hydroxyl groups in the 6-, 7-, or 8-positions have been described. ${ }^{120,}{ }^{130}$ The 6-, 7-, and 8-hydroxy metabolites of warfarin are more polar and bind less well to albumin, probably determining their absence in plasma and presence in urine. ${ }^{120}$ No metabolic product of a coumarin or indandione has been shown to have anticoagulant activity.

A metabolic product of phenindione imparts a red color to alkaline human urine ${ }^{36}$; this color has resulted in mistaken diagnoses of hematuria. The red color in the urine disappears when acid is added. Structurally related indandiones have been used as industrial dyes. Diphenadione is yellow in alkaline solution, thereby creating no problems in misinterpretation of the color of the urine.

Administration of vitamin $\mathrm{K}$ does not alter metabolic transformation of bishydroxycoumarin but does appear to accelerate the rate of disappearance of labeled bishydroxycoumarin from the liver. ${ }^{85}$

\section{Variability}

One of the major problems in the clear definition of the pharmacologic properties of oral anticoagulants is a marked variability in responsiveness: between species, between individuals, and in the same individual under differing conditions. Species differences are so marked that considerable caution is necessary in extrapolation of effects in one or even several types of animals to man. ${ }^{176}$ There are marked interindividual differences in the rate of metabolism of a given drug in man. More than threefold differences in rates of disappearance of bishydroxycoumarin and warfarin from plasma have been reported. ${ }^{1,176}$, ${ }_{177}$ Daily maintenance doses may vary by 
as much as tenfold. Many other elements such as nutritional state, vitamin $K$ intake, age, sex, rate of hepatic synthesis of clotting factors, etc., may be of even greater importance. Marked sensitivity or resistance to oral anticoagulants appears, in rare instances, to be related to genetic factors. ${ }^{1}$ Whether less marked interindividual variability also has some genetic determinants has not yet been defined. O'Reilly and Aggeler ${ }^{121}$ have described a family showing hereditary resistance to warfarin. The average daily dose of warfarin to maintain prothrombin time in a therapeutic range was 49 standard deviations from the mean. The same subject needed only one-half to one-fifth the usual dose of vitamin $K_{1}$ to reverse the anticoagulant effect. Six of eight members of the patient's family were also resistant to the effects of warfarin.

Although the administration of a single dose of one of these drugs to a healthy individual on separate occasions brings about a reproducible plasma concentration of drug at a given interval, the presence of certain diseases is associated with considerable intraindividual variation. The influence of systemic disease upon dose requirements appears to be related chiefly to changes in hepatic function which influence rates of synthesis of critical clotting factors. No major change in activity of drug-metabolizing enzymes ${ }^{63}$ or in the metabolism of the anticoagulant ${ }^{23}$ have been demonstrated under these circumstances. Changes in gastrointestinal function which bring about a decrease in intake or absorption of vitamin $\mathrm{K}$ or of orally administered anticoagulant can also alter response to a given dose. Since, with the exception of acenocoumarin, anticoagulants are not excreted unaltered in significant amounts by the kidney, it is unlikely that decreased renal excretion is responsible for the increased sensitivity of patients with chronic renal disease to these drugs. A more likely explanation for the increased incidence of hemorrhagic complications in these patients is the presence of multiple other hemostatic abnormalities secondary to the renal disease itself.

\section{Drug inferaction: Effect on} intraindividual variability in response

Tolerance to repeated doses of an anticoagulant does not occur except under circumstances in which other pharmacologic agents have brought about a change in activity of drug-metabolizing enzymes or some other form of drug interaction. ${ }^{174}$ In recent years a multiplicity of agents having an effect on anticoagulant dosage have received attention because of the significant effect they may have upon management of therapy. The various mechanisms through which drugs interact include: altered intestinal absorption, changes in transport (protein binding), altered metabolism of drug or its antagonist, effects upon receptor site, altered excretion, and chelation. To date, no evidence for the latter two mechanisms in interactions of drugs with oral anticoagulants has been presented.

The chief drug interaction influencing intestinal absorption is the indirect one in which various intestinal antibiotics may influence synthesis or absorption of vitamin $K_{1}$, lessening the continuous stimulus by vitamin $K_{1}$ of production of clotting factors and thus increasing the sensitivity of the individual to a given dose of oral anticoagulant.

Several drugs are thought to decrease dosage requirements of anticoagulant by displacing the anticoagulant from its binding site or by preventing initial binding to protein, thus increasing the concentration of free anticoagulant in plasma and the amount of drug present at its receptor site. Phenylbutazone ${ }^{2}$ appears to act through competitive inhibition while clofibrate functions by way of noncompetitive inhibition. ${ }^{16,} 159$ Salicylates may also influence anticoagulant dosage in this manner, although they have been shown to have an intrinsic anticoagulant effect as well. ${ }^{31,33,55,152}$ Oxyphenbutazone ${ }^{58}$ and phenyramidol ${ }^{27,156}$ also decrease anticoagu- 
lant requirements, presumably by inhibition of activity of hepatic microsomal drugmetabolizing enzymes; oxyphenbutazone may also have an effect upon protein binding of drug.

Other drugs have been reported to potentiate the effect of oral anticoagulants, but their mechanism of interaction has not been defined; these include D-thyroxine, ${ }^{143}$ androgens, ${ }^{131,}{ }_{143}$ haloperidol, ${ }^{115}$ acetaminophen, ${ }^{5}$ methylphenidate, ${ }^{62}$ quinidine, ${ }^{80}$ and several monamine oxidase inhibitors (tranylcypromine and nialamide). ${ }^{133}$ Iproniazid has no enhancing effect, while the action of other monamine oxidase inhibitors lies between these extremes.

Many drugs bring about an increase in the required dose of oral anticoagulant through induction of increased activity of hepatic microsomal coumarin-metabolizing enzymes; those in which clinical effects have been described include many barbital derivatives ${ }^{42,45,71,135}$ (phenobarbital, heptabarbital, amobarbital), glutethimide, ${ }^{40,71}$ chloral hydrate, ${ }^{43}$ and griseofulvin. ${ }^{28} \mathrm{Al}$ though many other agents are known to produce drug tolerance by means of this mechanism (sulfonylureas, meprobamate, antihistamines, alcohol, caffeine), a clinical effect upon anticoagulant requirements has not yet been described.

On the other hand, several investigators have recently reported that coumarin derivatives can affect the action of other drugs. Bishydroxycoumarin potentiates the effect of diphenylhydantoin. ${ }^{68}$ Simultaneous administration of bishydroxycoumarin and tolbutamide may result in protracted hypoglycemia $^{158}$; phenindione does not affect tolbutamide metabolism. ${ }^{82}$

Recently, Schrogie and associates ${ }^{144}$ have reported that oral contraceptives, by increasing vitamin $\mathrm{K}$-dependent clotting factor activity, bring about an increase in dosage of bishydroxycoumarin required for desired anticoagulant effect. Administration of multimethylated xanthines is followed by a decrease in prothrombin time in dogs receiving bishydroxycoumarin. ${ }^{54}$ The need for an increase in dose of anti- coagulant has been reported in patients receiving methylxanthines. ${ }^{18}$

\section{Side effects of oral anticoagulants}

Some of the additional effects of these agents may be related directly or indirectly to their primary mechanism of action in suppression of synthesis of coagulation factors, while other actions appear entirely unrelated. Several deserve considerable further investigation because of potential therapeutic utility.

Martius and Nitz-Litzow ${ }^{92-94}$ have shown that very large doses of bishydroxycoumarin inhibit oxidative phosphorylation. Phosphorylation appears to be inhibited at every step in electron transport. ${ }^{38,39,47}$ Phenindione does not display this effect. Whether this action is initiated through inhibition of ubiquinone function or by means of another mechanism is not yet clear. No decrease in oxidative enzyme activity is demonstrable in the liver of anticoagulated animals.

Coumarin derivatives display considerable antibacterial activity in vitro ${ }^{22,66,83}$, 168-170 which is thought to be related to uncoupling of oxidative phosphorylation. ${ }^{167}$ However, if bishydroxycoumarin-treated rabbits are injected intracutaneously with hemolytic streptococci, infection is more extensive than that in controls. ${ }^{166}$ The absence of fibrin in tissues of anticoagulated animals has been proposed as the factor contributing to increased spread of infection.

Fontaine and colleagues ${ }^{57}$ have reported that phenindione has an anti-inflammatory effect equivalent to that of phenylbutazone in rats with edema secondary to carageenin injections in the foot pad. Other anticoagulants are considerably less effective. A similar effect can be demonstrated in ultraviolet-induced erythema in guinea pig skin.

Of possible therapeutic potential is the demonstration by a number of observers of the beneficial effects of anticoagulants in the reduction of spontaneous metastases from malignant neoplasms. The effect of anticoagulants on this phenomenon ap- 
pears to parallel the depression of prothrombin activity. Cancer cells contain an agent which induces fibrin formation. ${ }^{119}$ The presence of a microthrombus around embolic tumor cells appears to contribute to adherence and penetration of these cells. ${ }^{184}$ In both transplanted and autochthonous tumors in animals, administration of anticoagulants brings about a significant decrease in number and frequency of spontaneous metastases. ${ }^{32,} 138,139$, ${ }_{183}$ Since treatment with warfarin inhibits the motility of cancer cells in vivo in rabbit ear chambers, Thornes and associates $^{165}$ have proposed that the uncoupling of oxidative prosphorylation might play a role in the inhibition of motility; administration of vitamin $\mathrm{K}_{1}$ restores cancer cell motility. In addition, bishydroxycoumarin has a direct cytotoxic effect on human cancer cells in vitro. ${ }^{87}$ Recently Michaels $^{105}$ has reported a retrospective study of cancer incidence and mortality rate in a group of 540 patients receiving long-term oral anticoagulants for prevention and treatment of thrombotic disease. Incidence of cancer was comparable to that predicted from statistics for that region. Eight deaths from cancer would have been expected during the 1,569 patient-years of observation, while only one was observed. Another patient who died from an unrelated cause had hepatic metastases from an undetected neoplasm at autopsy. Although, as Michaels is aware, the number of patients is too small for demonstration of valid statistical differences, this study should provide the stimulus for future prospective investigations.

Oral anticoagulants have also been used as an aid in the study of extramedullary erythropoiesis. After carbon tetrachlorideinduced hepatic injury, mitotically active hematopoietic cells of nonhepatic origin localize in the liver, presumably trapped in the liver by a fibrin network, a mechanism similar to that thought to bring about hepatic metastases of malignant neoplasms. The administration of warfarin prevents the development of these colony-forming units; concurrent administration of vita$\min K_{1}$ restores to normal the number of colony-forming units in the liver of mice treated with $\mathrm{CCl}_{4}$ and warfarin. The authors have questioned whether the establishment of hematopoietic colony-forming units in "normal" sites of extramedullary hematopoiesis, such as the spleen, might be adversely affected by anticoagulants. ${ }^{171}$

Additional pharmacologic actions have also been described. Warfarin sodium has bronchodilator activity, being about 50 per cent as active as aminophylline..$^{20}$ On swine coronary arteries both bishydroxycoumarin and warfarin have vasodilator activity comparable to that of nitroglycerin. ${ }^{19}$ Bishydroxycoumarin in high concentration increases total coronary flow in the isolated perfused dog heart but also has a depressant effect upon cardiac contractile force and increases total myocardial oxygen consumption; no effect could be demonstrated with warfarin. ${ }^{129}$

Phenindione has antithyroid activity in rats, blocking uptake of $\mathbf{I}^{131}$ as effectively as propylthiouracil. ${ }^{180}$ Other oral anticoagulants do not display this effect which, with phenindione, cannot be blocked by administration of vitamin $K_{1}$. The 48 hour $\mathbf{I}^{131}$ uptake was at or below normal in five patients receiving phenindione; uptake increased after the drug was discontinued.

Both coumarin and indandione derivatives (bishydroxycoumarin, ${ }^{51}$ ethylbiscoumacetate, ${ }^{160}$ and phenindione ${ }^{164}$ ) have a uricosuric effect, producing reversible impairment of urate reabsorption by renal tubules. Acenocoumarin and anisindione have no appreciable uricosuric action.

Recently, Sekhar ${ }^{147}$ has reported that diphenadione reduces serum cholesterol, triglyceride and phospholipid levels, and aortic plaque formation in atherosclerotic cockerels and pigeons. Simultaneous administration of vitamin $K_{1}$ does not alter this effect. George and associates ${ }^{64}$ have shown that phenylindandione and phenprocoumon accelerate clearing of $I^{131}$ triolein from the bloodstream. 
Table I. Oral anticoagulants

\begin{tabular}{|c|c|c|c|}
\hline Drug & $\begin{array}{c}\text { Usual loading dose } \\
\text { (mg. to } 30 \% \\
\text { prothrombin activity) }\end{array}$ & $\begin{array}{c}\text { Usual daily } \\
\text { maintenance dose } \\
\text { (mg.) }\end{array}$ & $\begin{array}{l}\text { Interval to } \\
\text { maximum effect } \\
\text { (hours) }\end{array}$ \\
\hline \multicolumn{4}{|l|}{ Coumarins } \\
\hline Bishydroxycoumarin & $400-700$ & 25- 150 & $36-72$ \\
\hline Ethyl biscoumacetate & $1,800-3,000$ & $200-1,200$ & $18-36$ \\
\hline Warfarin sodium & $30-\quad 60$ & 3 15 & $36-72$ \\
\hline Cyclocumarol & $150-400$ & $25-175$ & $24-48$ \\
\hline Phenprocoumon & $18-30$ & 1- 6 & $36-72$ \\
\hline Acenocoumarin & $30-\quad 60$ & $2-\quad 16$ & $24-36$ \\
\hline \multicolumn{4}{|l|}{ Indandiones } \\
\hline Phenindione & $400-700$ & 25- 200 & $24-36$ \\
\hline Diphenadione & $30-\quad 60$ & 3- $\quad 15$ & $60-84$ \\
\hline Anisindione & $250-550$ & $25-200$ & $24-48$ \\
\hline
\end{tabular}

\section{Considerations in clinical management}

Choice of drug; induction and maintenance dosage. Table I lists some of the more commonly used oral anticoagulants with ranges for usual loading and maintenance doses and times required to achieve the desired increase in one-stage prothrombin time, based upon our experience with these agents. Investigators, using other criteria, have reported values which differ from those in Table I. "Loading dose" refers to the total dose of drug required to depress the Quick one-stage prothrombin activity to a value less than 30 per cent. Time intervals are measured to the peak effect rather than to the first evidence of anticoagulant effect. Ranges have been used because of the marked interindividual variability in response.

Although much has been written about choice of drug, other than for exclusion of drugs because of toxic effects upon hematopoiesis, no single agent has been shown to have characteristics which would justify priority in clinical use. The most important consideration is the experience a clinician has had with the use of a particular drug. From the point of view of cost, bishydroxycoumarin is one of the least expensive. A greater fluctuation in day-today level of prothrombin activity has been attributed to the shorter-acting drugs but, if these compounds are administered more frequently (e.g., a twice-daily dosage schedule), an impressive degree of stability can be achieved. ${ }^{36}$ It has been proposed that more potent drugs which have a lower plasma concentration might display less variation with respect to half-life ${ }^{175}$; however, Solomon and Schrogie ${ }^{157}$ have not been able to correlate marked differences in individual response to a fixed dose of bishydroxycoumarin with differences in half-life of drug in plasma. Weiner ${ }^{175}$ has proposed that longer-acting drugs can be more readily managed if one gives a relatively large intermittent maintenance dose only after prothrombin activity increases following the maximum depression from the preceding dose. This presupposes that the greater fluctuation in prothrombin activity which is likely to occur with this approach does not contribute to a decrease in therapeutic effectiveness.

Recently, O'Reilly and associates ${ }^{122}$ have suggested a different approach to the initiation of therapy. Rather than utilizing a relatively large loading dose of drug (e.g., $50 \mathrm{mg}$. of warfarin), they suggest continued administration of a moderate-sized daily dose (e.g., $15 \mathrm{mg}$. of warfarin) until prothrombin activity has reached the desired level. As might be expected, this means a greater delay before "therapeutic" levels of prothrombin activity are achieved. 
However, they argue that this longer interval reflects changes in the rate of depression of factor VII activity while factors II, IX, and X fall just as rapidly as with a larger induction dose. They suggest that, since these latter clotting factors may play a greater role in stimulating propagation of thrombus than does factor VII, the slower depression of prothrombin activity by this approach may be as satisfactory in preventing further thromboembolism as the more rapid depression achieved by the use of larger initial doses. In our opinion, these suppositions may be valid provided that treatment with an oral anticoagulant is accompanied by immediate and adequate heparin therapy for at least five to seven days while factors II, IX, and $\mathrm{X}$ are slowly decreasing.

In no other area of pharmacotherapy is individualization more important than in the administration of oral anticoagulants. Some of the numerous variables which may affect individual dosage requirement have been discussed. We and many others have noted as much as a tenfold interindividual variation in dose of drug required for maintenance of a stable depression of prothrombin activity in patients being treated for thrombotic disease. Other than fundamental genetic differences in rates of drug metabolism, age, sex, "body content" of vitamin $K$, the presence of debilitating disease which may affect hepatic function, and intake of other "interacting" drugs appear to be the most common factors influencing this variability. In addition, occasional patients with extensive thrombotic disease may be unusually resistant.

Experience has shown that, regardless of cause, many patients with pretreatment prothrombin activity of less than 70 per cent will display increased sensitivity to oral anticoagulants. Smaller loading and maintenance doses of drug should be utilized for these patients. On the other hand, as the usually sensitive seriously ill patient responds to therapy of his primary disease (e.g., congestive heart failure), daily maintenance doses of oral antico- agulant may have to be increased several fold to maintain a constant effect.

Combined use of heparin. As has been mentioned, the maximum depression of all of the four clotting factors known to be affected by oral anticoagulants may not be achieved until five to seven days after the initial dose of drug. Although the relative influence of each factor in the promotion of thrombus propagation in man is not known, on the basis of experiments in animals, factors IX and X may be of particular importance. An increasing number of clinicians have been extending the initial period of combined therapy with both heparin and an oral anticoagulant to a minimum period of five to ten days. If only short-term therapy (seven to ten days) is planned, many are recommending the use of heparin alone.

When both heparin and oral anticoagulants are administered, blood for estimation of one-stage prothrombin time must be obtained at a time when residual plasma heparin content has reached a low level. Otherwise, the heparin in plasma will bring about prolongation of prothrombin time and thus prevent proper interpretation of the effect of the oral anticoagulant on clotting factor activity. This problem is a significant one when heparin is given by subcutaneous injection. The most practical method for simultaneous use of these agents is the intermittent intravenous injection of heparin at four- to eight-hour intervals, the blood for determination of prothrombin time being obtained just prior to the next dose of heparin.

Laboratory control. All of the early and many of the recent assessments of the clinical efficacy of anticoagulants in the treatment of thrombotic disease in the United States have been based upon laboratory control by the one-stage prothrombin time of Quick. ${ }^{132}$ However, numerous modifications of this procedure have been devised and advocated as being "more effective" in control of anticoagulant therapy, particularly in the reduction of hemorrhagic complications. Some of the 
modifications which are most frequently utilized include: (1) the Quick test with the use of a $\mathrm{BaSO}_{4}$-adsorbed plasma in place of saline for determining dilution curves $^{137}$; (2) several modifications of the Quick method determined on diluted plasma ${ }^{86,153}$; (3) the prothrombin and proconvertin ( $P$ \& $P$ ) test and its modifications ${ }^{127} ;(4)$ "thrombotest" ${ }^{125}$; (5) partial thromboplastin times. ${ }^{52}$

Each of these procedures has been promoted with claims of greater sensitivity, easier reproducibility, better standardization, etc., but what has frequently been ignored is that a given result by one method is in no way comparable to the result obtained when another technique is used. The lack of equivalence of these tests has been pointed out by a number of observers. ${ }^{104,136,137,163,181}$

Obviously, the optimal laboratory control of anticoagulant therapy should be determined by that regimen which provides maximum protection against thromboembolism while minimizing serious hemorrhagic complications. While the definitive answer to this problem has not yet been provided, the best available data have been derived from studies utilizing the one-stage Quick prothrombin time. The optimal range, as will be discussed later, appears to be a prolongation of Quick prothrombin time of between two and three times the control value. This range by the Quick method represents more intensive anticoagulant therapy than that recommended by the advocates of either the $\mathrm{P} \& \mathrm{P}$ or thrombotest techniques. As Miale ${ }^{104}$ points out, a prothrombin time (Quick) of two and one-half times the normal is equivalent to a value of 1 per cent by the P \& $\mathrm{P}$ method and 0.6 per cent by the thrombotest. To date, there is no evidence that any of the proposed modifications of the Quick procedure are superior in the clinical management of patients as assessed by the combined criteria of prevention of thromboembolic and hemorrhagic complications of therapy at equivalent levels of anticoagulation.
Although these tests are simple, continued supervision of personnel and standardization of reagents are necessary to assure reproducibility of results. ${ }^{137}$ The tissue "thromboplastin" extracts show considerable lability and variability and must be carefully selected and repeatedly checked. An understanding by the physician of the nature of the procedure and methods of reporting results are critical to proper interpretation and management of the level of anticoagulant therapy. Results have been reported as:

1. Prothrombin time. The time for clotting of a normal "control" plasma is reported for comparison with that of the patient's plasma.

2. Percentage prothrombin activity. These percentage values are derived from a curve made by testing various dilutions of normal plasma with saline or $\mathrm{BaSO}_{4}$ adsorbed plasma. The dilution curve obtained with saline differs from that obtained with adsorbed plasma containing additional factor $V$ and fibrinogen. What many physicians who administer anticoagulants in their daily practice have failed to understand is that this reported percentage value cannot be linearly related on a percentage basis to the magnitude of anticoagulant effect. The dilution curve is hyperbolic in shape; a prolongation of a few seconds in prothrombin time will be reported as a large difference in percentage, while in the therapeutic range, where the slope of the curve changes, a considerable increase in prothrombin time will be reported as a very small change in percentage (Fig. 2). In managing therapy one must know whether saline or adsorbed plasma was used in preparing the dilution curve; because of differing slopes of the curve, a prothrombin activity of 15 per cent with adsorbed plasma is equivalent to an activity of approximately 25 per cent with the saline dilution curve.

3. Prothrombin index. This percentage is derived by dividing the control prothrombin time in seconds by patient's prothrombin time and multiplying by 100 . A pro- 


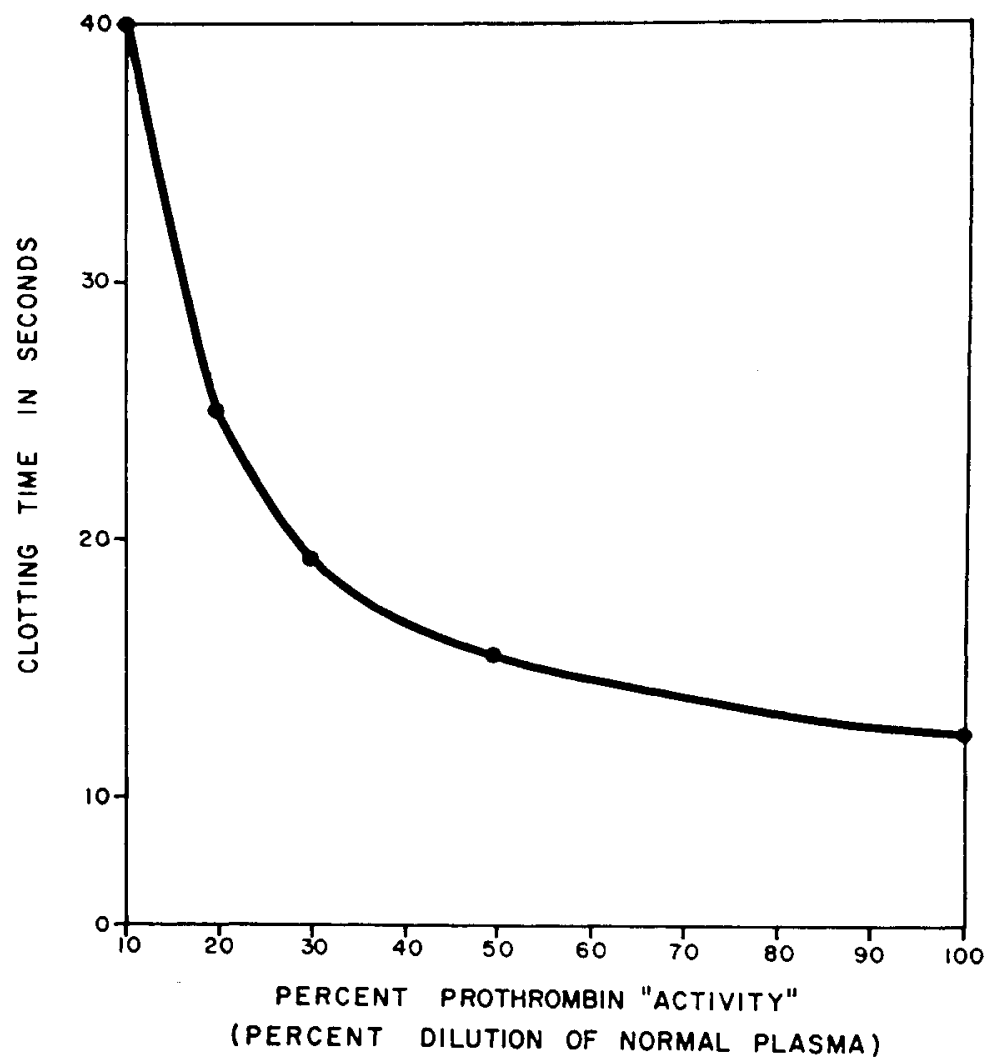

Fig. 2. Curve for Quick one-stage prothrombin activity (constructed from determinations of "accelerated clotting time" of dilutions of normal plasma with saline).

thrombin index of 50 per cent is equivalent to a prothrombin activity of approximately 20 per cent. The hazard is that misinterpretation of the prothrombin index as prothrombin activity may lead the physician to underestimate the oral anticoagulant effect and to administer more of the agent, placing the patient in jeopardy of serious hemorrhage.

Intensity and duration of therapy. Although information comparing thromboembolic complication rates in patients managed at differing levels of intensity of therapy is scarce, what information is available is in support of more intensive therapy. In the anticoagulant treatment of acute myocardial infarction, the frequency of thromboembolic complications was reduced by about 40 per cent in those subjects with prothrombin times maintained at or above 25 seconds (about 23 per cent pro- thrombin activity, Quick) as opposed to those patients with less intensive treatment. ${ }^{189}$ In a recent randomized prospective study, patients with pulmonary embolism allocated to a group treated in the 10 to 29 per cent range of prothrombin activity had a significantly lower incidence of thromboembolic complications during therapy than those treated in a range of 30 to 49 per cent prothrombin activity (Quick). ${ }^{37}$ Sevitt and Innes, ${ }^{151}$ in studying incidence at autopsy of thrombosis and embolism in a group of injured patients receiving prophylactic anticoagulants, found a higher frequency of thromboembolic sequelae in those patients with a Quick prothrombin time maintained at less than twice normal (prothrombin activity of 24 per cent in their laboratory).

Duration of anticoagulant treatment must be related to type and severity of 
thrombotic disease. However, as far as venous thromboembolism is concerned, our recent experience with extending the period of therapy by continuing treatment on an outpatient basis has brought about a significant reduction in rates of recurrent thromboembolism in those patients receiving more prolonged treatment. ${ }^{37}$ Since anticoagulant therapy in outpatients must of necessity be regulated with less frequent laboratory measurements than those provided in a hospital environment, maintenance of prothrombin activity between 30 and 50 per cent is usually recommended to lessen the frequency of hemorrhagic complications.

Some clinicians have proposed that, when anticoagulant treatment is to be terminated, the drug dosage be gradually reduced to lessen the hazard of "rebound thromboembolism." The validity of this approach has never been documented. In fact, the little reliable data which are available do not support this premise. ${ }^{150}$

Toxicity. In addition to hemorrhagic complications, several coumarin derivatives have been shown to be associated on rare occasions with other side effects. ${ }^{103}$ Transient alopecia, severe dermatitis, ${ }^{142}$ skin necrosis, and generalized urticaria have been reported after ingestion of warfarin and other coumarins. Ulcerations of the mouth have appeared after administration of acenocoumarin. Gastrointestinal disturbances (nausea, vomiting, diarrhea) appear rarely in association with bishydroxycoumarin or ethylbiscoumacetate therapy..$^{34}$ Toxic side effects have been reported more frequently in association with use of phenindione. These include agranulocytosis, renal lesions (albuminuria, polyuria, renal failure), dermatitis (including exfoliative dermatitis), diarrhea and steatorrhea, paralysis of accommodation and blurring of vision, anemia, and hepatitis. ${ }^{107}$

Bleeding. Some form of hemorrhage appears in approximately 10 per cent of hospitalized patients receiving oral anticoagulants and in almost one in three individuals receiving long-term therapy as out- patients. The great majority of these episodes are minor and can be managed without termination of treatment. Deaths are rare. The apparent causes of hemorrhage are multiple and complex. Some of the variables which may influence the development of bleeding include: (1) inordinate depression of clotting factor activity; (2) a possible toxic effect upon capillary walls; and (3) changes in platelet function. Since multiple coagulation factors are depressed by oral anticoagulants, efforts have been made to correlate bleeding with selective depression of individual factors. Many conflicting reports have appeared. Since after five to seven days of treatment levels of activity of factors II, VII, IX, and X are markedly decreased, the incrimination of any single factor is difficult. Baugh ${ }^{13}$ has reported that the levels of these factors are no different in patients who are bleeding than in those who are not.

When very excessive or lethal doses of anticoagulant have been ingested by animals ${ }^{15,}{ }_{95}$ or man, ${ }^{180}$ widespread dilatation of small blood vessels has been noted. With one known exception, ${ }^{154}$ no histologic changes in the vessel wall itself have been detectable. An "increased vascular fragility" has been postulated. ${ }^{5 \text {, }}$ ${ }_{182}$ The petechiae which have been noted in patients with coumarin overdosage could be secondary to the possible effects of these agents on platelet adhesiveness rather than to any structural alteration of the vascular wall itself. The only evidence for an alteration in vascular integrity is the demonstration by Nelson ${ }^{112}$ that bishydroxycoumarin increases the rate of loss of T1824-labeled protein from the bloodstream of rabbits.

A series of studies which may contribute to our understanding of the pathogenesis of bleeding are those performed by Jaques ${ }^{74}$ in rabbits and rats. The incidence of spontaneous hemorrhage in animals receiving large doses of anticoagulant alone is very low. However, if one superimposes any other measure which 
affects another phase of hemostasis (platelets, the vessel wall), the frequency of lethal hemorrhage increases markedly. Some of these other measures include administration of $\mathrm{P}^{32}$, reserpine, steroids, or production of "stress" (electric or insulin shock, injection of formalin, sham operation, frostbite, etc.). Mortality rate from hemorrhage increases with the increase in hypocoagulability produced by the anticoagulant and with the increase in intensity of the measure affecting another phase of hemostasis. Unfortunately, since so many factors may influence hemostasis in anticoagulant-treated patients, the validity of this thesis is extremely difficult to document in man, particularly the possible effects of "stress" upon the vascular phase of hemostasis.

Since developments are relatively recent, the quantitative role of drug interaction in the etiology of anticoagulant-induced bleeding in man has also not yet been adequately investigated. It appears, however, that this factor may contribute to an appreciable proportion of hemorrhagic episodes. MacDonald and Robinson $^{91}$ have recently reported that in 14 of 67 episodes of bleeding, enzyme induction was a contributing factor; two patients died. Forty of 52 patients with myocardial infarction receiving anticoagulants were also treated with barbiturates; they required higher doses of anticoagulants and therapy was more difficult to control. Since barbiturates and other sedatives (chloral hydrate, glutethimide) are administered so frequently, the majority of reports of bleeding brought about by this mechanism have been related to these drugs. Enzyme induction by these sedatives brings about an increased rate of metabolism of the anticoagulant and necessitates an increase in the dose required to maintain the desired effect; if the sedative is then discontinued the prothrombin time will increase markedly and bleeding may occur. Microsomal enzyme induction may appear within two to seven days after administration of these drugs $^{40,43}$ and may last for as long as six weeks after therapy has been discontinued. ${ }^{135}$ The other forms of drug interaction act more directly to increase sensitivity to anticoagulants.

In a recent survey of our experience with anticoagulant therapy in 2,468 episodes of thromboembolism, bleeding occurred in 7.9 per cent of the courses of treatment. Major bleeding which was defined as hemorrhage of such magnitude as to require termination of anticoagulant therapy appeared in 2.4 per cent; greater than one half of these hemorrhagic events were gastrointestinal in origin, followed in order of frequency by vaginal bleeding, hemorrhage from an operative wound, and severe epistaxis. Minor bleeding, requiring an adjustment in drug dosage without termination of therapy, was present in the remaining 5.5 per cent with the predominant source being the genitourinary tract (hematuria) followed by epistaxis, minor bleeding from a wound, vagina or gastrointestinal tract, ecchymoses, etc. About one third of these episodes appeared to be primarily related to associated heparin therapy rather than to the oral anticoagulant. Less frequently, bleeding may occur in brain and spinal cord, wall of the intestine, pericardium, ovary, adrenal glands, and other areas. ${ }^{111}$

Bleeding usually occurs at values for prothrombin activity by the Quick procedure of 15 per cent or below. ${ }^{192}$ Very frequently, and particularly at higher prothrombin activity, bleeding is related to the presence of a pre-existing organic lesion. On many occasions such lesions, especially in the gastrointestinal tract, have been previously unrecognized. Organic lesions responsible for hemorrhage can be identified in at least one half of patients bleeding at levels of prothrombin activity of 15 per cent or above. ${ }^{191}$

Reversal of anticoagulant effect. Vita$\min K_{1}$ (2-methyl-3-phytyl-1,4-naphthoquinone) corrects the abnormalities in coagulation produced by oral anticoagulants. An equimolar amount of vitamin 
$\mathrm{K}_{3}$ (2-methyl-1,4-naphthoquinone) is considerably less effective, probably because of its much more rapid conjugation and excretion. ${ }^{76}$ When isotopically labeled vita$\min K_{1}$ is administered to anticoagulanttreated rats, there is a positive correlation between shortening of prothrombin time and hepatic content of vitamin $K_{1}$. Since vitamin $K_{1}$ is metabolized very slowly, the minimum effective dose of this agent should be utilized if further oral anticoagulant therapy is contemplated; otherwise, considerable resistance to the effect of subsequent administration of anticoagulant may be encountered, in some instances for periods of several weeks or more. Administration of doses of vitamin $K_{1}$ of 2.5 to $5 \mathrm{mg}$, either orally or intravenously, can have an appreciable effect in shortening a prolonged prothrombin time within four to eight hours. ${ }^{61}$ Since recent studies have shown a considerable interindividual variability in response of prothrombin times of warfarin-treated patients to small doses of vitamin $\mathrm{K}_{1}$ ( $5 \mathrm{mg}$. or less), ${ }^{190}$ in instances of life-threatening hemorrhage, doses of $50 \mathrm{mg}$. will produce a more predictable response. ${ }^{134}$ Bleeding produced by excessive dosage of anticoagulant is usually treated with a larger dose of vitamin $\mathrm{K}_{\mathbf{1}}$ than is bleeding secondary to unusual sensitivity to an "ordinary" dose of drug. In addition, the more prolonged the prothrombin time, the larger the dose of vitamin $K_{1}$ needed for prompt reversal of effect. In the rare instance of very serious massive bleeding, correction of coagulative abnormalities can also be brought about by administration of whole blood or plasma.

Contraindications to anticoagulant therapy. The decision to administer anticoagulants must be made by balancing the risk of serious or lethal hemorrhage against the potential for equally morbid or fatal thromboembolic disease. The hazard of bleeding is especially great in patients with other hemostatic abnormalities, recent cerebral hemorrhage, recent operations upon the central nervous system or eye, or ulcerative lesions of the gastrointestinal, respiratory, or genitourinary systems (especially prostate gland). Of equal importance in contributing to an increased risk of bleeding are an uncooperative patient, inadequate laboratory control, and uninformed or casual medical supervision. Other entities which contribute to a higher risk include severe hypertension, subacute bacterial endocarditis, pericarditis, severe hepatic disease, and certain nutritional problems (particularly deficiencies of vitamins $\mathrm{C}$ and $\mathrm{K}$ ). Many of these and other contraindications which have been proposed are relative rather than absolute. In many instances anticoagulants can be administered with relative safety (the risk of serious bleeding being less than the hazard of fatal thromboembolism) if dosage is carefully managed and laboratory control is rigidly supervised.

Some indications for therapy. Only the more important indications and a few of the clinical trials will be noted. By far, the most important indication for anticoagulant therapy, in terms of both numbers of patients and value, is the prevention and treatment of deep venous thrombosis and pulmonary embolism. Since numerous studies have pointed out the extreme difficulty in clinical recognition of venous thromboembolism, prophylaxis will be superior to therapy of established disease in the prevention of morbidity and death. The many diseases associated with an increased risk for development of secondary thromboembolic disease and the case for much more extensive use of prophylactic anticoagulants in patients confined to bed with these conditions have been repeatedly emphasized. ${ }^{11,35,148} \mathrm{~A}$ number of trials have shown that anticoagulants can bring about a reduction of up to tenfold in the incidence of thromboembolism in high-risk patients with obstetrical and surgical problems. ${ }^{21,49,141,149} \mathrm{~A}$ significant decrease in lethal thromboembolism is also achieved when anticoagulants are administered to patients with congestive heart failure. ${ }^{4}$

Numerous trials of anticoagulants in the 
treatment of clinically established venous thrombosis and pulmonary embolism have provided data which, when compared by retrospective analysis with prior series of patients treated by bed rest alone, substantiate the significant contribution of anticoagulants to the reduction of morbidity and death from this disease. However, it was not until 1960 that the first adequately designed randomized prospective clinical trial of anticoagulants in the treatment of pulmonary embolism was reported by Barritt and Jordan. ${ }^{12}$ By the time 19 patients had been followed in the control group (bed rest alone) and 16 in the treated group, five control subjects had died from pulmonary embolism and five others had developed nonfatal pulmonary emboli, while none of the treated patients had any evidence of recurrent disease ( $p$ $<0.001$ ). A comparable controlled trial of treatment of deep venous thrombosis alone has not yet been performed, but morbidity and death in anticoagulanttreated patients is so low as to leave little doubt regarding its value. ${ }^{37}$

The value of anticoagulants in the treatment of acute myocardial infarction is much more controversial. Despite all the recent debate concerning selection of patients and the influence of multiple other variables, the summary by Douglas ${ }^{50}$ of the more important clinical trials indicates a 50 per cent over-all reduction in mortality rate for treated patients as compared to that for control patients. With the advent of coronary care units, the current aggressive attitude toward prevention and treatment of arrhythmias and earlier mobilization of the patient, the reduction in mortality rate brought about by anticoagulants may be considerably less in future trials. Many investigators believe that whatever reduction in mortality rate is achieved may be related less to a decrease in deaths from extension of the myocardial infarct or recurrent infarction than to a decrease in incidence of fatal pulmonary embolism.

Although many studies have supported the long-term use of anticoagulants (one year or more) in lowering the incidence of recurrent myocardial infarction, ${ }^{16,100,}{ }^{173}$ a well-controlled recent investigation ${ }^{146}$ has not provided support for their use; in that study, however, the prothrombin and proconvertin ( $\mathrm{P} \& \mathrm{P}$ ) test was utilized and the intensity of treatment was moderate (only 13 per cent of $\mathrm{P} \& \mathrm{P}$ values below 30 per cent, about 50 per cent by the Quick method). As Loeliger and associates ${ }^{\text {ss }}$ have recently demonstrated, the intensity of anticoagulant treatment may be the critical factor in achieving a significant reduction in morbidity and death; in a doubleblind clinical trial, rigorously controlled anticoagulant therapy brought about a significant reduction in incidence of cardiovascular deaths.

The validity of anticoagulant therapy in the management of severe angina pectoris and "impending myocardial infarction" is also difficult to assess. True randomization of patients has not been carried out. Several groups have reported an appreciable reduction in frequency of myocardial infarction particularly within the first few months of initiation of therapy. ${ }^{114,}{ }^{185}$

One point of general agreement has been reached concerning the use of anticoagulants in cerebrovascular disease. Anticoagulants have no place in the treatment of acute completed strokes and may actually be harmful by increasing the risk of fatal cerebral hemorrhage. In addition, there is no unequivocal evidence that longterm anticoagulant therapy favorably inHuences the incidence of recurrent cerebral infarction although McDevitt and McDowell $^{97}$ have recently reported that anticoagulant-treated patients had a lesser morbidity and mortality rate within the first year after a completed stroke. Although the data are by no means definitive, several trials provide some evidence that anticoagulants may be of value in reducing the extent of neurologic deficit in patients with "stroke in evolution."10, 26 Assessment of the value of these drugs in "transient ischemic attacks" is particularly 
difficult because of problems of accurate diagnosis and the variability in frequency and severity of attacks. Nevertheless, a number of observers, ${ }^{9,56,155}$ including a large cooperative study, ${ }^{9}$ have reported a reduction in frequency of attacks in patients receiving anticoagulants.

Although no controlled prospective trials have yet been conducted, long-term anticoagulant therapy appears to be of benefit in patients at risk from arterial embolism, including cerebral embolism. The subjects at particular risk are those with mitral stenosis and atrial fibrillation secondary to rheumatic heart disease. Several observers have reported a reduction in frequency of arterial embolism of the order of tenfold during periods of anticoagulant treatment. ${ }^{41,96,126} \mathrm{~A}$ delay of several days or more before initiation of anticoagulants in patients with recent cerebral emboli may be prudent in order to reduce the risk of hemorrhage into an infarcted area. Similarly, the prophylactic value of anticoagulant therapy in patients undergoing cardioversion and in those with prosthetic heart valves is difficult to assess but seems established. ${ }^{3,60}$ In the former group there is a statistically valid decrease in the frequency of embolic episodes occurring between six hours and six days after conversion. ${ }^{17}$

The use of anticoagulants has been advocated in the management of atherosclerotic peripheral arterial disease and in retinal arterial and venous thrombosis, but no clear evidence of benefit has yet been presented.

\section{References}

1. Aggeler, P. M., and O'Reilly, R. A.: The pharmacological basis of oral anticoagulant therapy, Thromb. Diath. Haemorrh. 2l (Suppl.):227-256, 1966.

2. Aggeler, P. M., O'Reilly, R. A., Leong, L., and Kowitz, P. E.: Potentiation of anticoagulant effect of warfarin by phenylbutazone, New Eng. J. Med. 276:496-501, 1967.

3. Akbarian, M., Austen, W. G., Yurchak, P. M., and Scannell, J. G.: Thromboembolic complications of prosthetic cardiac valves, Circulation 37:826-831, 1968 .
4. Anderson, G. M., and Hull, E.: The effect of Dicumarol upon the mortality and incidence of thromboembolic complications in congestive heart failure, Amer. Heart J. 39:697-702, 1950.

5. Antlitz, A. M., Mead, J. A., Jr., and Tolentino, M. A.: Potentiation of oral anticoagulant therapy by acetaminophen, Curr. Ther. Res. 10:501-507, 1968.

6. Arora, R. B., and Mathur, C. N.: Relationship between structure and anticoagulant activity of coumarin derivatives, Brit. J. Pharmacol. 20:29-35, 1963.

7. Arora, R. B., Mathur, C. N., and Seth, S. D. S.: Anticoagulant and cardiovascular actions of calophyllolide, an indigenous complex coumarin, Arch. Int. Pharmacodyn. 139:75-84, 1962.

8. Axelrod, J., Cooper, J. R., and Brodie, B. B.: Estimation of Dicumarol, 3,3'-methylenebis (4-hydroxycoumarin) in biological fluids, Proc. Soc. Exp. Biol. Med. 70:693-695, 1949.

9. Baker, R. N.: An evaluation of anticoagulant therapy in the treatment of cerebrovascular disease: Report of the Veterans Administration Cooperative Study of Atherosclerosis, Neurology Section, Neurology 11:132-138, 1961.

10. Baker, R. N., Broward, J. A., Fang, H. C., Fisher, C. M., Groch, S. N., Heyman, A., Karp, H. R., McDevitt, E., Scheinberg, P., Schwartz, W., and Toole, J. F.: Anticoagulant therapy in cerebral infarction: Report on cooperative study, Neurology 12:823-835, 1962.

11. Barker, N. W., Nygaard, K. K., Walters, W. and Priestley, J. T.: A statistical study of postoperative venous thrombosis and pulmonary embolism. II. Predisposing factors, Mayo Clin. Proc. 16:1-5, 1941.

12. Barritt, D. W., and Jordan, S. C.: Anticoagulant drugs in the treatment of pulmonary embolism: A controlled trial, Lancet 1:1309. 1312, 1960.

13. Baugh, C. W.: An investigation of the hemorrhagic diathesis in patients receiving coumarin and indanedione anticoagulants, Canad. Med. Ass. J. 92:116-120, 1965.

14. Berman, H. J.: Anticoagulant-induced alterations in haemostasis, platelet thrombosis, and vascular fragility in the peripheral vessels of the hamster cheek pouch, in MacMillian, $R$. L., and Mustard, J. F., editors: International Symposium Anticoagulants and Fibrinolysins, Philadelphia, 1961, Lea \& Febiger, Publishers, pp. 95-107.

15. Bingham, J. B., Meyer, O. O., and Pohle, F. J.: Studies on the hemorrhagic agent $3,3^{\prime}$ methylenebis (4-hydroxycoumarin). I. Its effect on the prothrombin and coagulation 
time of the blood of dogs and humans, Amer. J. Med. Sci. 202:563-578, 1941.

16. Bjerkelund, C. J.: The effect of long-term treatment with dicoumarol in myocardial infarction: A controlled clinical study, Acta Med. Scand. 158: (Suppl. 330), 1957.

17. Bjerkelund, C. J., and Orning, O. M.: The efficacy of anticoagulant therapy in preventing embolism related to D.C. electrical conversion of atrial fibrillation, Amer. J. Cardiol. 23:208-216, 1969 .

18. Blake, O. R., Ashwin, J. G., and Jaques, L. B.: An assay for the antithrombotic activity of anticoagulants, J. Clin. Path. 12: 118-122, 1959.

19. Blake, T. M., Wood, E. G., Jr., O'Moore, D., and Neel, R. G.: The vasodilating effects of coumarin derivatives, Amer. J. Med. Sci. 243:598-602, 1962.

20. Blumberg, H., Dayton, H. B., and Gordon, S. M.: Bronchodilator action of the anticoagulant warfarin sodium, Science 127:188, 1958.

21. Brambel, C. E., Hunter, R. E., and Fitzpatrick, V. deP.: Prophylactic use of anticoagulants in the puerperal period (Dicumarol, heparin and Link compound 63), Bull. School Med. Univ. Maryland 35:91-103, 1950.

22. Brodersen, R., and Kjaer, A.: The antibacterial action and toxicity of some unsaturated lactones, Acta Pharmacol. Toxicol. 2:109-120, 1946.

23. Brodie, B. B., Burns, J. J., and Weiner, M.: Metabolism of drugs in subjects with Laennec's cirrhosis, Med. Exp. 1:290-292, 1959.

24. Brodie, B. B., Weiner, M., Burns, J. J., Simson, G., and Yale, E. K.: The physiological disposition of ethyl biscoumacetate (Tromexan) in man and a method for its estimation in biological material, J. Pharmacol. Exp. Ther. 106:453-463, 1952.

25. Campbell, H. A., and Link, K. P.: Studies on the hemorrhagic sweet clover disease. IV. The isolation and crystallization of the hemorrhagic agent, J. Biol. Chem. 138:21-33, 1941.

26. Carter, A. B.: Anticoagulant treatment in progressing stroke, Brit. Med. J. 2:70-73, 1961.

27. Carter, S. A.: Potentiation of the effect of orally administered anticoagulants by phenyramidol hydrochloride, New Eng. J. Med. 273:423-426, 1965.

28. Catalano, P. M., and Cullen, S. I.: Warfarin antagonism by griseofulvin, Clin. Res. 14: 266, 1966. (Abst.)

29. Christensen, F.: Studies on the fate of intravenous dicoumarol in the rat, Acta Pharmacol. Toxicol. 21:307-312, 1964.

30. Christensen, F.: Studies on the fate of dicou- marol-14 $\mathrm{C}$ in the rat, Acta Pharmacol. Toxicol. 22:141-151, 1965.

31. Clark, B. B., and Spitalny, M.: Prothrombinopenic activity of the salicylates and pharmacologically related drugs, Fed. Proc. 5:171-172, 1946.

32. Cliffton, E. E., and Agostino, D.: Factors affecting the development of metastatic cancer. Effect of alterations in clotting mechanism, Cancer 15:276-283, 1962.

33. Coburn, A. F.: Salicylate therapy in rheumatic fever: A rational technique, Bull. Hopkins Hosp. 73:435-464, 1943.

34. Cohen, J.: Unusual gastrointestinal reaction to bishydroxycoumarin (Dicumarol), Amer. Heart J. 76:144, 1968.

35. Coon, W. W., and Coller, F. A.: Some epidemiologic considerations of thromboembolism, Surg. Gynec. Obstet. 109:487-501, 1959.

36. Coon, W. W., Duff, I. F., Hodgson, P. E., and Dennis, E. W.: Therapeutic evaluation of a new anticoagulant, phenylindandione, Ann. Surg. 138:467-475, 1953.

37. Coon, W. W., and Willis, P. W., III.: Assessment of the effectiveness of anticoagulant treatment of venous thromboembolism, Ann. Surg. 170:559-568, 1969.

38. Cooper, C., and Lehninger, A. L.: Oxidative phosphorylation by an enzyme complex from extracts of mitochondria. I. The span Bhydroxybutyrate to oxygen, J. Biol. Chem. 219:489-506, 1956.

39. Cooper, C., and Lehninger, A. L.: Oxidative phosphorylation by an enzyme complex from extracts of mitochondria. III. The span cytochrome $\mathrm{C}$ to oxygen, J. Biol. Chem. 219: 519-529, 1956.

40. Corn, M.: Effect of phenobarbital and glutethimide on the biologic half-life of warfarin, Thromb. Diath. Haemorrh. 16:606-612, 1966.

41. Cosgriff, S. W.: Chronic anticoagulant therapy in recurrent embolism of cardiac origin, Ann. Intern. Med. 38:278-287, 1953.

42. Cucinell, S. A., Conney, A. H., Sansur, M., and Burns, J. J.: Drug interactions in man. I. Lowering effect of phenobarbital on plasma levels of bishdroxycoumarin (Dicumarol) and diphenylhydantoin (Dilantin), Clin. PharMACOL. Ther. 6:420-429, 1965.

43. Cucinell, S. A., Odessky, L., Weiss, M., and Dayton, P. G.: The effect of chloral hydrate on bishydroxycoumarin metabolism: A fatal outcome, J. A. M. A. 197:366-368, 1966.

44. Cunningham, G. M., MeNicol, G. P., and Douglas, A. S.: Effect of anticoagulant drugs on platelet aggregation in the Chandler's tube, Lancet 1:729-730, 1965.

45. Dayton, P. G., Tarcan, Y., Chenkin, T., and Weiner, M.: The influence of barbiturates 
on coumarin plasma levels and prothrombin response, J. Clin. Invest. 40:1797-1802, 1961.

46. Descours, C., Appeau, A., and Delahaye, J. P.: Expérimentation clinique d'un nouvel anticoagulant dérivé du dicourmarol: le $3,3^{\prime}$ méthyl-thiopropylidène-bis (4-hydroxycoumarine), Lyon Med. 212:1089-1098, 1964.

47. Devlin, T. M., and Lehninger, A. L.: Oxidative phosphorylation by an enzyme complex from extracts of mitochondria. II. The span B-hydroxybutyrate to cytochrome C, J. Biol. Chem. 219:507-518, 1956.

48. Deželić, M., and Trkovnik, M.: Syntheses of some 4-hydroxycoumarins and their condensation products with aldehydes and carboxylic acids. The anticoagulant activity of some 4-hydroxycoumarin derivatives, J. Med. Chem. 7:284-288, 1964.

49. Dick, W., Matis, P., and Mayer, W.: Results of alternating anticoagulant prophylaxis in surgery, Thromb. Diath. Haemorrh. 3:11-19, 1959.

50. Douglas, A. S.: Anticoagulant therapy, Philadelphia, 1962, F. A. Davis Company, p. 214.

51. Dreyfuss, F., and Czaczkes, J. W.: The uricosuric action of bishydroxycoumarin ( Dicumarol), Arch. Intern. Med. 102:389-391, 1958.

52. Eastham, R. D.: Improved control of longterm anticoagulant therapy, Brit. Med. J. 1:337-340, 1968 .

53. Faivre, G., Gilgenkrantz, J. M., Cherrier, F., Tenette, C., and Barrucand, D.: Etude critique, a partir de 43 observations, d'un anticoagulant coumarinique: Le dicoumoxyl (méthoxy-1-bis (hydroxy-4-coumarinyl-3) 2, 2-éthane), Semaine Hop. Paris 39:2392-2399, 1963.

54. Field, J. B., Larsen, E. G., Spero, L., and Link, K. P.: Studies in the hemorrhagic sweet clover disease. XIV. Hyperprothrombinemia induced by methylxanthines and its effect on the action of 3,3'-methylenebis-(4hydroxycoumarin), J. Biol. Chem. 156:725737, 1944.

55. Field, J. B., Spero, L., and Link, K. P.: Hypoprothrombinemia induced in the dog by salicylic acid, Amer. J. Physiol. 159:40-46, 1949.

56. Fisher, C. M.: Anticoagulant therapy in cerebral thrombosis and cerebral embolism: A national cooperative study, interim report, Neurology 11:119-131, 1961.

57. Fontaine, L., Grand, M., Quentin, Y., and Merle, S.: Activité anti-inflammatoire comparée de substances anticoagulantes: Mode d'action de la phénylindanedione, Med. Pharmacol. Exp. 13:137-154, 1965.

58. Fox, S. L.: Potentiation of anticoagulants caused by pyrazole compounds, J. A. M. A. 188:320-321, 1964.

59. Fulton, G. P., Akers, R. P., and Lutz, B. R.: White thromboembolism with vascular fragility in the hamster cheek pouch after anticoagulants, Blood 8:140-152, 1953.

60. Gadboys, H. L., Litwak, R. S., Niemetz, J., and Wisch, N.: Role of anticoagulants in preventing embolization from prosthetic heart valves, J. A. M. A. 202:282-286, 1967.

61. Gamble, J. R., Dennis, E. W., Coon, W. W., Hodgson, P., Willis, P. W., III, MaCris, J. A., and Duff, I. F.: Clinical comparison of vi$\operatorname{tamin} K_{1}$ and water-soluble vitamin $K$, Arch. Intern. Med. 95:52-58, 1955.

62. Garrettson, L. K., Perel, J. M., and Dayton, P. G.: Methylphenidate interaction with both anticonvulsants and ethyl biscoumacetate: A new action of Methylphenidate, J. A. M. A. 207:2053-2056, 1969.

63. Gaudette, L. E., Maickel, R. P., and Brodie, B. B.: Oxidative metabolism of drugs by vertebrates, Fed. Proc. 17:370, 1958. (Abst.)

64. George, E. P., Hall, G. V., and Farkas, G. S.: Lipaemic clearing action of artificial anticoagulants, Nature 187:782-784, 1960.

65. Gonyea, L. M., and Bridges, R. A.: Studies of the mode of action of dicoumarin, Biochem. Pharmacol. 14:579-587, 1965.

66. Goth, A.: The antibacterial properties of Dicumarol, Science 101:383, 1945.

67. Gumińska, M., Eckstein, M., Stachurska, B., and Sulko, J.: The anticoagulant activity of 3,3'-(p-alkylthiobenzylidene) - bis - 4 - hydroxycoumarins and their oxidation products, Thromb. Diath. Haemorrh. 17:277-286, 1967.

68. Hansen, J. M., Kristensen, M., Skovsted, L., and Christensen, L. K.: Dicoumarol-induced diphenylhydantoin intoxication, Lancet 2: 265-266, 1966.

69. Hausner, E. P., Shafer, C. L., Corson, M., Johnson, O., Trujillo, T., and Langham, W.: Clinical evaluation of dicumarinyl derivatives with a metabolic study of the radioactively labeled anticoagulants in animals, Circulation 3:171-181, 1951.

70. Horlick, L.: The adhesive index, a measure of platelet stickiness. Its response to myocardial injury and to anticoagulant treatment, in MacMillian, R. L., and Mustard, J. F., editors: International Symposium Anticoagulants and Fibrinolysins, Philadelphia, 1961, Lea \& Febiger, Publishers, pp. 56-67.

71. Hunninghake, D. B., and Azarnoff, D. L.: Drug interactions with warfarin, Arch. Intern. Med. 121:349-352, 1968.

72. Hunter, R. B., and Shepherd, D. M.: Chemistry of coumarin anticoagulant drugs, Brit. Med. Bull. 11:56-61, 1955.

73. Jaques, L. B.: The physiology of the anti- 
coagulants, Rev. Hémat. 10:379-384, 1955.

74. Jaques, I. B.: Stress and multiple-factor etiology of bleeding, Ann. New York Acad. Sci. 115:78-96, 1964.

75. Jaques, L. B., Froese, E. L., O’Toole, R., and Spinks, J. W. T.: Relation between duration of hypoprothrombinemia with Dicumarol and the level of the drug in the liver, Arch. Int. Pharmacodyn. 111:478-489, 1957.

76. Jaques, L. B., Millar, G. J., and Spinks, J. W. T.: The metabolism of the K-vitamins, Schweiz. Med. Wschr. 84:792-796, 1954.

77. Jewell, P., Pilkington, T., and Robinson, B.: Heparin and ethyl biscoumacetate in prevention of experimental venous thrombosis, Brit. Med. J. 1:1013-1016, 1954.

78. Johnson, S. A.: The changes in the blood coagulation mechanisms wrought by the administration of the oral anticoagulants, in MacMillian, R. L., and Mustard, J. F., editors: International Symposium Anticoagulants and Fibrinolysins, Philadelphia, 1961, Lea \& Febiger, Publishers, pp. 47-55.

79. Kazmier, F. J., Spittell, J. A., Jr., Thompson, J. J., Jr., and Owen, C. A., Jr.: Effect of oral anticoagulants on factors VII, IX, X, and II, Arch. Intern. Med. 115:667-673, 1965.

80. Koch-Weser, J.: Quinidine-induced hypoprothrombinemic hemorrhage in patients on chronic warfarin therapy, Ann. Int. Med. 68: 511-517, 1968.

81. Koptelova, M. N.: Omephine, a new anticoagulant, Fed. Proc. 22(Trans. Suppl.): T1256-T1258, 1963.

82. Kristensen, M., and Hansen, J. M.: Potentiation of the tolbutamide effect by dicoumarol, Diabetes 16:211-214, 1967.

83. Lacerda, P. M. G. de, Jr.: Antibacterial properties of dicoumarol, Rev. Fac. Med. Vet. Univ. São Paulo 3:155-156, 1945. (Chem. Abst. 40:7295, 1946.)

84. LaTona, S. R., and LeFevre, F.: Relationship of Dicumarol absorption to gastric free hydrochloric acid, Amer. Heart J. 38:743$746,1949$.

85. Lee, C. C., Trevoy, L. W., Spinks, J. W. T., and Jaques, L. B.: Dicumarol labeled with $\mathrm{C}^{14}$, Proc. Soc. Exp. Biol. Med. 74:151-155, 1950.

86. Link, K. P.: The anticoagulant from spoiled sweet clover hay, Harvey Lect. 39:162-216, 1943-1944.

87. Lisnell, A., and Mellgren, J.: Effect of heparin, protamine, dicoumarol, streptokinase and epsilon-amino- $\mathrm{N}$-caproic acid on the growth of human cells in vitro, Acta Path. Microbiol. Scand. 57:145-153, 1963.

88. Loeliger, E. A., Hensen, A., Kroes, F., van Dijk, L. M., Fekkes, N., de Jonge, H., and Hemker, H. C.: A double-blind trial of long- term anticoagulant treatment after myocardial infarction, Acta Med. Scand. 182:549-566, 1967.

89. Lowenthal, J., and Birnbaum, H.: Vitamin $\mathrm{K}$ and coumarin anticoagulants: Dependence of anticoagulant effect on inhibition of vitamin $\mathrm{K}$ transport, Science 164:181-183, 1969.

90. Lowenthal, J., and MacFarlane, J. A.: The nature of the antagonism between vitamin $\mathrm{K}$ and indirect anticoagulants, J. Pharmacol. Exp. Ther. 143:273-277, 1964.

91. MacDonald, M. G., and Robinson, D. S.: Clinical observations of possible barbiturate interference with anticoagulation, J. A. M. A. 204:97-100, 1968.

92. Martius, C., and Nitz-Litzow, D.: Uber den Wirkungsmechanismus des Dicumarols und verwandter Verbindungen, Biochim. Biophys. Acta 12:134-140, 1953.

93. Martius, C., and Nitz-Litzow, D.: Oxydative Phosphorylierung und Vitamin K Mangel, Biochim. Biophys. Acta 13:152-153, 1954.

94. Martius, C., and Nitz-Litzow, D.: Über den Nachweis einer Wirkung von Vitamin $K_{1}$ in vitro auf die oxydative Phosphorylierung, Biochim. Biophys. Acta 13:289-290, 1954.

95. McCarter, J. C., Bingham, J. B., and Meyer, O. O.: Studies on the hemorrhagic agent 3,3'-methylenebis (4-hydroxy-coumarin). IV. The pathologic findings after the administration of Dicumarol, Amer. J. Path. 20:65I659, 1944.

96. McDevitt, E., Carter, S. A., Gatje, B. W., Foley, W. T., and Wright, I. S.: Use of anticoagulants in treatment of cerebral vascular disease: Ten-year experience in treatment of thromboembolism, J. A. M. A. 166:592-597, 1958.

97. McDevitt, E., and McDowell, F. H.: Anticoagulant therapy of the completed stroke, Geriatrics 23:135-140, 1968.

98. Mead, J. A. R., Smith, J. N., and Williams, R. T.: Studies in detoxication. 71. The metabolism of hydroxycoumarins, Biochem J. 68:61-67, 1958.

99. Mead, J. A. R., Smith, J. N., and Williams, R. T.: Studies in detoxication. 72. The metabolism of coumarin and of O-coumaric acid, Biochem J. 68:67-74, 1958.

100. Medical Research Council Report. An assessment of long-term anticoagulant administration after cardiac infarction, Brit. Med. J. 1:803-810, 1959.

101. Merz, W. R.: Der Übergang der Dicumarine von Mutter auf Kind durch die Muttermilch (Ausstellung), in Koller, T., and Merz, W. R., editors: Thrombosis and embolism: Proceedings of the first international Conference 
Basel 1954, Basel, 1955, Benno Schwabe \& Co., pp. 275-280.

102. Meunier, P. P.: Du dicoumarol aux antivitamines $\mathrm{K}$ artificielles, Brit. J. Nutr. 2:396$400,1949$.

103. Meyler, L.: Side effects of drugs: Adverse reactions as reported in the medical literature of the world 1963-1965, Vol. 5, Amsterdam, 1966, Excerpta Medica Foundation, pp. 499507.

104. Miale, J. B.: Laboratory control of anticoagulant therapy, J. A. M. A. 180:736-738, 1962.

105. Michaels, L.: Cancer incidence and mortality in patients having anticoagulant therapy, Lancet 2:832-835, 1964.

106. Millar, G. J., Mersereau, M. O., Lowenthal, J., and Jaques, L. B.: Distribution of phenylindanedione in blood and tissues after oral and intravenous administration, Thromb. Diath. Haemorrh. 2:236-249, 1958.

107. Mohamed, S. D.: Sensitivity reaction to phenindione with urticaria, hepatitis, and pancytopenia, Brit. Med. J. 2:1475-1476, 1965.

108. Murphy, E. A., and Mustard, J. F.: Dicumarol therapy: Some effects on platelets and their relationship to clotting tests, Circ. Res. 8:1187-1199, 1960.

109. Murphy, E. A., and Mustard, J. F.: Dicumarol therapy and platelet turnover, Circ. Res. 9:402-406, 1961.

110. Nagashima, R., O’Reilly, R. A., and Levy, G.: Kinetics of pharmacologic effects in man: The anticoagulant action of warfarin, Cr.IN. Pharmacol. Ther. 10:22-35, 1969.

111. Nalbandian, R. M., Mader, I. J., Barrett, J. L., Pearce, J. F., and Rupp, E. C.: Petechiae, ecchymoses, and necrosis of skin induced by coumarin congeners: Rare, occasionally lethal complications of anticoagulant therapy, J. A. M. A. 192:603-608, 1965.

112. Nelson, T. E., Jr.: Effect of Dicumarol on blood vascular integrity in the rabbit, Circ. Res. 8:889-896, 1960.

113. Neumann, W., Dahl, J., and Remde, W.: Thromboembolieprophylaxe und Thrombosetherapie mit Chlorphenylindandion: Vergleich mit Phenylindandion und Phenylpropylcumarin, Munchen Med. Wschr. 107:16021605, 1965.

114. Nichol, E. S., Phillips, W. C., and Casten, G. G.: Virtue of prompt anticoagulant therapy in impending myocardial infarction: Experiences with 318 patients during a 10-year period, Ann. Intern. Med. 50:1158-1173, 1959.

115. Oakley, D. P., and Lautch, H.: Haloperidol and anticoagulant treatment, Lancet 2:1231, 1963.
116. Oliver, M. F., Roberts, S. D., Hayes, D., Pantridge, J. F., Suzman, M. M., and Bersohn, I.: Effect of atromid and ethyl chlorophenoxyisobutyrate on anticoagulant requirements, Lancet 1:143-144, 1963.

117. Olson, R. E.: Effect of actinomycin D upon vitamin $\mathrm{K}$-induced prothrombin formation in dicumarolized rats, J. Clin. Invest. 44:1082, 1965. (Abst.)

118. Olwin, J. H.: Discussion, in Flynn, J. E.: Blood clotting and allied problems: Transactions of the First Conference February 16-17, 1948, New York, New York, New York, 1948, Josiah Macy, Jr. Foundation, pp. 103-114.

119. O'Meara, R. A. Q.: Coagulative properties of cancers, Irish J. Med. Sci. (6th series): 474-479, 1958.

120. O'Reilly, R. A.: Interaction of the anticoagulant drug warfarin and its metabolites with human plasma albumin, J. Clin. Invest. 48:193-202, 1969.

121. O'Reilly, R. A., and Aggeler, P. M.: Coumarin anticoagulant drugs: Hereditary resistance in man, Fed. Proc. 24:1266-1273, 1965.

122. O'Reilly, R. A., Aggeler, P. M., Kowitz, P. E., Kropatkin, M., and Leong, L. S.: New approaches to the initiation of long-term anticoagulant therapy, Clin. Res. 13:94, 1965. (Abst.)

123. O'Reilly, R. A., Aggeler, P. M., and Leong, L. S.: Studies on the coumarin anticoagulant drugs: The pharmacodynamics of warfarin in man, J. Clin. Invest. 42:1542-1551, 1963.

124. O'Reilly, R. A., Aggeler, P. M., and Leong, L. S.: Studies on the coumarin anticoagulant drugs: A comparison of the pharmacodynamics of Dicumarol and warfarin in man, Thromb. Diath. Haemorrh. 11:1-22, 1964.

125. Owren, P. A.: Thrombotest: A new method for controlling anticoagulant therapy, Lancet 2:754-758, 1959.

126. Owren, P. A.: The results of anticoagulant therapy in Norway, Arch. Intern. Med. 111: 240-247, 1963.

127. Owren, P. A., and Aas, K.: The control of Dicumarol therapy and the quantitative determination of prothrombin and proconvertin, Scand. J. Clin. Lab. Invest. 3:201-208, 1951.

128. Petryaevskaya, N. V., and Val'dman, A. V.: Pharmacological study of high molecular anticoagulants, Fed. Proc. 24(Trans. Suppl.): T591-T592, 1965.

129. Powell, W. J., Jr., Clancy, R. I., Graham, T. P., Jr., and Gilmore, J. P.: Myocardial effects of bishydroxycoumarin and warfarin, Amer. J. Cardiol. 20:648-653, 1967.

130. Pulver, R., Montigel, C., and Exer, B.: Úber den Stoffwechsel von 4-Oxycumarin-Derivaten in Koller, T., and Merz, W. R., editors: 
Thrombosis and embolism: Proceedings of the first international Conference Basel 1954, Basel, 1955, Benno Schwabe \& Co., pp. 232-238.

131. Pyörälä, K., and Kekki, M.: Decreased anticoagulant tolerance during methandrostenolone therapy, Scand. J. Clin. Lab. Invest. 15: 367-374, 1963.

132. Quick, A. J.: The hemorrhagic diseases and the physiology of hemostasis, Springfield, Ill., 1942, Charles C Thomas, Publisher.

133. Reber, K., and Studer, A.: Beeinflussung der Wirkung einiger indirekter Antikoagulantien durch Monoaminoxydase-Hemmer, Thromb. Diath. Haemorrh. 14:83-87, 1965.

134. Rehbein, A., Jaretzki, A., III, and Habif, D. V.: The response of Dicumarol-induced hypoprothrombinemia to vitamin $K_{1}$, Ann. Surg. 135:454-469, 1952.

135. Robinson. D. S., and MacDonald, M. G.: The effect of phenobarbital administration on the control of coagulation achieved during warfarin therapy in man, J. Pharmacol. Exp. Ther. 153:250-253, 1966.

136. Rodman, T., and Pastor, B. H.: Control of anticoagulant therapy with the thrombotest, J. A. M. A. 180:739-743, 1962.

137. Rodman, T., Pastor, B. H., and Hoxter, B. L.: II. Problems encountered in the laboratory control of anticoagulant therapy with the one-stage determination of prothrombin complex activity, Amer. J. Med. 31:555-563, 1961.

138. Ryan, J. J., Ketcham, A. S., and Wexler, H.: Reduced incidence of spontaneous metastases with long-term Coumadin therapy, Ann. Surg. 168:163-168, 1968.

139. Ryan, J. J., Ketcham, A. S., and Wexler, H.: Warfarin treatment of mice bearing autochthonous tumors: Effect on spontaneous metatases, Science 162:1493-1494, 1968.

140. Saidi, P., Hoag, M. S., and Aggeler, P. M.: Transplacental transfer of bishydroxycoumarin in the human, J. A. M. A. 191:761-763, 1965.

141. Salzman, E. W., Harris, W. H., and DeSanctis, R. W.: Anticoagulation for prevention of thromboembolism following fractures of the hip, New Eng. J. Med. 275: 122-130, 1966.

142. Schiff, B. L., and Kern, A. B.: Cutaneous reactions to anticoagulants, Arch. Derm. 98: 136-137, 1968.

143. Schrogie, J. J., and Solomon, H. M.: The anticoagulant response to bishydroxycoumarin. II. The effect of D-thyroxine, clofibrate, and norethandrolone, Clin. Pharmacol. Ther. 8:70-77, 1967.

144. Schrogie, J. J., Solomon, H. M., and Zieve, P. D.: Effect of oral contraceptives on vita- min $\mathrm{K}$-dependent clotting activity, CLIN. Pharmacol. Ther. 8:670-675, 1967.

145. Schulert, A. R., and Weiner, M.: The physiologic disposition of phenylindanedione in man, J. Pharmacol. Exp. Ther. 110:451-457, 1954.

146. Seaman, A. J., Griswold, H. E., Reaume, R. B., and Ritzman, L. W.: Prophylactic anticoagulant therapy for coronary artery disease: A seven-year controlled study, J. A. M. A. 189:183-187, 1964.

147. Sekhar, N. C.: Hypocholesterolemic effect of diphenyl acetyl-indandione, Fed. Proc. 27: 221, 1968. (Abst.)

148. Sevitt, S.: Venous thrombosis and pulmonary embolism: Their prevention by oral anticoagulants, Amer. J. Med. 33:703-716, 1962.

149. Sevitt, S., and Gallagher, N. G.: Prevention of venous thrombosis and pulmonary embolism in injured patients: A trial of anticoagulant prophylaxis with phenindione in middle-aged and elderly patients with fractured necks of femurs, Lancet 2:981-989, 1959.

150. Sevitt, S., and Innes, D.: Evidence against "rebound" thrombosis after stopping oral anticoagulant drugs, Lancet 2:974-975, 1963.

151. Sevitt, S., and Innes, D.: Prothrombin-time and thrombotest in injured patients on prophylactic anticoagulant therapy, Lancet 1: 124-129, 1964.

152. Shapiro, S., Redish, M. H., and Campbell, H. A.: Studies on prothrombin: IV. The prothrombinopenic effect of salicylate in man, Proc. Soc. Exp. Biol. Med. 53:251-254, 1943.

153. Shapiro, S., and Weiner, M.: The dilution of plasma in estimating prothrombin activity, Acta Haemat. 3:241-247, 1950.

154. Shlevin, E. L., and Lederer, M.: Uncontrollable hemorrhage after dicoumarol therapy with autopsy findings, Ann. Intern. Med. 21:332-342, 1944 .

155. Siekert, R. G., Whisnant, J. P., and Millikan, C. H.: Surgical and anticoagulant therapy of occlusive cerebrovascular disease, Ann. Intern. Med. 58:637-641, 1963.

156. Solomon, H. M., and Schrogie, J. J.: The effect of phenyramidol on the metabolism of bishydroxycoumarin, J. Pharmacol. Exp. Ther. 154:660-666, 1966

157. Solomon, H. M., and Schrogie, J. J.: The anticoagulant response to bishydroxycoumarin. I. The role of individual variation, CLIN. Pharmacol. Ther. 8:65-69, 1967.

158. Solomon, H. M., and Schrogie, J. J.: Effect of phenyramidol and bishydroxycoumarin on the metabolism of tolbutamide in human subjects, Metabolism 16:1029-1033, 1967.

159. Solomon, H. M., and Schrogie, J. J.: The effect of various drugs on the binding of 
warfarin- ${ }^{14} \mathrm{C}$ to human albumin, Biochem. Pharmacol. 16:1219-1226, 1967.

160. Sougin-Mibashan, R., and Horwitz, M.: The uricosuric action of ethyl biscoumacetate, Lancet 1:1191-1197, 1955.

161. Spooner, M., and Meyer, O. O.: The effect of Dicumarol (3,3'-methylenebis 4-hydroxycoumarin) on platelet adhesiveness, Amer. J. Physiol. 142:279-283, 1944.

162. Stoll, W. G., and Litvan, F.: Der Einfluss der Substitution in 4-Oxycumarin-Derivaten aus die Gerinnungsvalenz des Blutes, in Koller, T., and Merz, W. R., editors: Thrombosis and embolism: Proceedings of the first international Conference Basel 1954, Basel, 1955, Benno Schwabe \& Co., pp. 244-250.

163. Tat, R. J., and Lewis, A. E.: Levels of equivalence for various measurements of coumarin activity, J. A. M. A. 180:744-746, 1962.

164. Thompson, G. R., Mikkelsen, W. M., and Willis, P. W., III: The uricosuric effect of certain oral anticoagulant drugs, Arthritis Rheum. 2:383-388, 1959.

165. Thornes, R. D., Edlow, D. W., and Wood, S., Jr.: Inhibition of locomotion of cancer cells in vivo by anticoagulant therapy. I. Effects of sodium warfarin on V2 cancer cells, granulocytes, lymphocytes and macrophages in rabbits, Bull. Hopkins Hosp. 123: 305-316, 1968.

166. Thurer, G. R., and Angevine, D. M.: Influence of Dicumarol on streptococcic infection in rabbits, Arch. Path. 48:274-277, 1949.

167. Ukita, T., and Ejima, A.: Mode of antibacterial activity of 3-acetyl-4-hydroxycoumarin and dehydroacetic acid. I, J. Pharm. Soc. Jap. 82:1625-1630, 1962.

168. Ukita, T., Mizuno, D. I., Tamura, T., Yamakawa, T., and Nojima, S.: The antibacterial properties of compounds containing the tricarbonylmethane group. II. III. Antibacterial properties of 3-alkylated or 3-acylated 4-hydroxycoumarins and of a related pyrone, J. Pharm. Soc. Jap. 71:234-243, 1951.

169. Ukita, T., Nojima, S., and Matsumoto, M.: The antibacterial properties of compounds containing the tricarbonylmethane group. IV. Syntheses of 3-alkylated or 3-acylated 4hydroxycoumarins and of a related pyrone, J. Amer. Chem. Soc. 72:5143-5144, 1950.

170. Ukita, T., Tamura, T., Matsuda, R., and Kashiwabara, E.: Antibacterial properties of compounds having tricarbonylmethane group in their structure. I. Antibacterial properties of 1,1-dimethyl-4-acyl-cyclohexanediones-3,5, dehydracetic acid and 3-acyl-4-hydroxycoumarins, Jap. J. Exp. Med. 20:109-115, 1949.
171. Varon, M. L., and Cole, L. J.: Hemopoietic colony-forming units in regenerating mouse liver: Suppression by anticoagulants, Science 153:643-644, 1966.

172. Venho, E. V.: Pharmakologische Untersuchungen über die Toxizität und die Antagonisten der synthetischen Antikoagulantien, Ann. Med. Exp. Fenn. 37: (Suppl. 6), 1959.

173. Veterans Administration Cooperative Study: Long-term anticoagulant therapy after myocardial infarction: A study of 747 patients in 15 hospitals, J. A. M. A. 193:929-934, 1965.

174. Weiner, M.: Pharmacological considerations of antithrombotic therapy, Advances Pharmacol. 1:277-307, 1962.

175. Weiner, M.: The significance of the physiologic disposition of drugs in anticoagulant therapy, Seminars Hemat. 1:345-374, 1964.

176. Weiner, M., Brodie, B. B., and Burns, J. J.: A comparative study of hypoprothrombinemic agents. The physiologic disposition and chemical pharmacology of coumarin and indandione compounds, in Koller, T., and Merz, W. R., editors: Thrombosis and embolism: Proceedings of the first international Conference Basel 1954, Basel, 1955, Benno Schwabe \& Co., pp. 181-193.

177. Weiner, M., Shapiro, S., Axelrod, J., Cooper, J. R., and Brodie, B. B.: The physiological disposition of Dicumarol in man, J. Pharmacol. Exp. Ther. 99:409-420, 1950.

178. Wessler, S., Reimer, S. M., and Sheps, M. C.: Biologic assay of a thrombosis-inducing activity in human serum, J. Appl. Physiol. 14: 943-946, 1959.

179. West, B. D., Preis, S., Schroeder, C. H., and Link, K. P.: Studies on the 4-hydroxycoumarins. XVII. The resolution and absolute configuration of warfarin, J. Amer. Chem. Soc. 83:2676-2679, 1961.

180. Williams, E. D., and Doniach, I.: The antithyroid activity of the anticoagulant phenylindanedione, J. Endocr. 21:421-431, 1961.

181. Willis, P. W., III, Coon, W. W., and Duff, I. F.: The management of anticoagulant therapy, Postgrad. Med. 27:85-93, 1960.

182. Wood, J. C., and Conn, H. L., Jr.: Prevention of systemic arterial embolism in chronic rheumatic heart disease by means of protracted anticoagulant therapy, Circulation 10:517-523, 1954.

183. Wood, J. S., Jr., Holyoke, E. D., and Yardley, J. H.: An experimental study of the influence of adrenal steroids, growth hormone, and anticoagulants on pulmonary metastasis formation in mice, Proc. Amer. Ass. Cancer Res. 2:157-158, 1956. (Abst.)

184. Wood, J. S., Jr., Holyoke, E. D., and Yardley, J. H.: Mechanisms of metastasis pro- 
duction by blood-borne cancer cells, Proc. Canad. Cancer Res. Conf. 4:167-223, 1961.

185. Wood, P.: Acute coronary insufficiency, in Pickering, G. W, editor: Symposium on Anticoagulant Therapy: Report of the Proceedings of a Symposium Held at the Royal Society Medicine on 18th and 19th November, 1960, London, 1961, Harvey \& Blythe, Ltd.

186. Wright, H. P.: The adhesiveness of blood platelets in rabbits treated with dicoumarol, J. Path. Bact. 57:382-385, 1945.

187. Wright, H. P., Kubik, M. M., and Hayden, M.: Recanalization of thrombosed arteries under anticoagulant therapy, Brit. Med. J. 1:1021-1023, 1953 .

188. Wright, H. P., Kubik, M. M., and Hayden, M.: Influence of anticoagulant administration on the rate of recanalization of experimental- ly thrombosed veins, Brit. J. Surg. 40:163166, 1952.

189. Wright, I. S., Marple, C. D., and Beck, D. F.: Myocardial infarction: Its clinical manifestations and treatment with anticoagulants; a study of 1,031 cases, New York, 1954, Grune \& Stratton, Inc., p. 348.

190. Zieve, P. D., and Solomon, H. M.: Variation in the response of human beings to vitamin $\mathrm{K}_{1}$, J. Lab. Clin. Med. 73:103-110, 1969.

191. Zweifler, A. J.: Relation of prothrombin concentration to bleeding during oral anticoagulant therapy: Its importance in detection of latent organic lesions, New Eng. J. Med. 267:283-285, 1962.

192. Zweifler, A. J., Coon, W. W., and Willis, P. W., III: Bleeding during oral anticoagulant therapy, Amer. Heart J. 71:118-123, 1966. 